\title{
PENGGUNAAN KATALIS PALADIUM DALAM REAKSI ARILASI n-OKTILSILAN DENGAN 2-IODIDA-5-METIL TIOFEN
}

\section{THE USE OF PALLADIUM CATALYST IN THE REACTION OF n-OCTYLSILANE WITH 2-IODO-5-METHYL THIOPHEN}

\author{
Aldes Lesbani*, Addy Rachmat, Risfidian Mohadi, Eliza \\ Jurusan Kimia Fakultas Matematika dan Ilmu Pengetahuan Alam, Universitas Sriwijaya \\ Kampus UNSRI Inderalaya, Ogan Ilir 30662, Sumatera Selatan \\ *e-mail: aldeslesbani@yahoo.com
}

\begin{abstract}
ABSTRAK
Telah dilakukan proses arilasi n-oktilsilan dengan 2-iodida-5-metil tiofen mengunakan katalis palladium dengan teknik reaksi kopling untuk mendapatkan variasi senyawa hasil arilasi. Produk hasil arilasi yang terbentuk dimurnikan dengan metode kromatografi kolom silika dengan eluen etil asetat dan dikarakterisasi menggunakan spektroskopi massa, spektroskopi ${ }^{1} \mathrm{H}$ NMR, ${ }^{13} \mathrm{C}$ NMR, dan DEPT-135. Hasil penelitian menunjukkan bahwa senyawa yang terbentuk dari hasil arilasi yakni tris(5-metil-2tiofen)oktilsilan yang berupa cairan tak berwarna dengan nilai $\mathrm{m} / \mathrm{z}$ sebesar 432 . Hasil pengukuran menggunakan spektroskopi ${ }^{1} \mathrm{H}$ NMR menghasilkan tujuh proton ekivalen. Pengukuran menggunakan spektroskopi ${ }^{13} \mathrm{C}$ NMR menghasilkan tiga belas karbon ekivalen yang kemudian dikonfirmasi dengan DEPT-135. Hasil karakterisasi menggunakan spektroskopi massa dan spektroskopi NMR ( $\mathrm{H}$ dan $\mathrm{C})$ menunjukkan senyawa hasil sintesis adalah tris(5-metil-2-tiofen)oktilsilan.
\end{abstract}

Kata kunci : arilasi, n-oktilsilan, 2-iodida-5-metil tiofen, palladium.

\begin{abstract}
Arylation of n-octylsilane with 2-iodo-5-methyl thiophen using palladium catalyst through coupling reaction to obtain various arylation product has been carried out. Product of arylation was purified using silica column chromatography with ethyl acetate as eluent and was characterized using mass spectroscopy, ${ }^{1} \mathrm{H},{ }^{13} \mathrm{C}$ and DEPT 135 NMR spectroscopy. The results showed that product of arylation was colorless oil with $\mathrm{m} / \mathrm{z} 432$ namely tris(5-methyl-2-thiophen)octylsilane. The spectrum of ${ }^{1} \mathrm{H}$ NMR resulted seven equivalent protons. The measurement using ${ }^{13} \mathrm{C}$ NMR resulted thirteen equivalent carbons, which was confirmed using DEPT-135. The results of characterization using mass spectroscopy and NMR spectroscopy ( $\mathrm{H}$ and $\mathrm{C}$ ) showed that the product of synthesis was tris(5-methyl-2-thophen)octylsilane.
\end{abstract}

Keywords : arylation, n-octylsilane, 2-iodo-5-methyl thiophen, palladium.

\section{PENDAHULUAN}

Pencarian senyawa-senyawa

kimia baru bagi kepentingan manusia terus dilakukan hingga saat ini. Berbagai bidang yang membutuhkan pengembangan senyawa-senyawa kimia baru seperti bidang kesehatan dalam rangka mencari obat-obat baru (Daiss, et.al., 2005) dan bidang pertanian dalam rangka mencari pestisida baru (Lesbani, 
dkk, 2012a). Dalam rangka pengembangan senyawa-senyawa kimia baru tersebut diperlukan suatu motode sintesis kimia yang cepat dalam artian sedikit tahapan sintesis serta dapat menghasilkan produk dengan selektifitas yang tinggi (Sato, et.al., 1998).

Salah satu metode sintesis senyawa kimia yang terus dikembangkan yakni reaksi kopling. Reaksi kopling merupakan reaksi penggabungan rantai karbon menjadi senyawa baru dengan menggunakan suatu katalis (Trost and Verhoeven, 1982). Dalam reaksi kopling selain reaktan memegang peranan penting juga pemilihan katalis yang tepat sangat berperan dalam menghasilkan produk dengan selektifitas yang tinggi (Tsuji, 2004).

Reaksi arilasi merupakan salah satu dari banyak reaksi kimia yang menggunakan metode reaksi kopling (Yamanoi, 2005). Reaksi arilasi merupakan proses penggabungan gugus aril dengan gugus organik lain menjadi senyawa kimia baru. Katalis yang biasa digunakan dalam proses arilasi pada umumnya logam paladium (Negishi, 2002). Walaupun beberapa katalis logam dan senyawa lain seperti iridium maupun rhodium dapat digunakan dalam proses arilasi, akan tetapi selektifitas yang dihasilkan tidak setinggi penggunaan katalis paladium (Yamanoi and Nishihara, 2006).

Lesbani, et al. (2010a) telah melaporkan penggunaan katalis paladium dalam proses arilasi berbagai senyawa organosilika dan organogermanium. Katalis paladium ini pula telah menghasilkan senyawa 5,5'bis(tris(trimethylsilyl)silanyl)-2,2'

bitiofene yang mempunyai sifat photoluminescence yang tinggi (2010b). Disamping itu pula Lesbani, dkk. (2012) telah mengaplikasikan penerapan reaksi arilasi dalam sintesis pestisida golongan flusilazol. Penelitian terbaru yang dilakukan Lesbani, dkk. (2013a,b) menunjukkan bahwa organosilika maupun organogermanium yang digunakan dapat bervariasi baik gugus aromatik maupun alifatik. Demikian pula senyawa aril yang digunakan bermacammacam dengan tingkat toleransi reaksi yang cukup baik (Lesbani, dkk., 2013b).

Berdasarkan penjelasan tersebut maka pada penelitian ini dilaporkan penggunaan katalis paladium dalam arilasi n-oktilsilan dengan 2-iodida-5metil tiofen. Produk arilasi yang dihasilkan diharapkan dapat menambah variasi senyawa yang berhasil diarilasi menggunakan katalis paladium dan dapat dimanfaatkan lebih lanjut bagi kepentingan manusia seperti penggunaaannya sebagai sensor, sebagai bahan baku sintesis obat dan pestisida, serta sebagai material luminescence.

\section{METODE PENELITIAN}

\section{Alat dan Bahan}

Bahan-bahan kimia yang
digunakan dalam penelitian inian
berkualitas analytical grade buatan Aldrich yakni n-oktilsilan, 2-iodida-5metil tiofen, paladium tersier tributilfosfin, diazabisiklo(2,2,2)oktan, dan tetrahidrofuran. Bahan-bahan kimia ini langsung digunakan tanpa pemurnian lebih lanjut kecuali tetrahidrofuran yang di distilasi menggunakan benzofenon dan logam natrium untuk diperoleh pelarut tetrahidrofuran bebas air. Hasil distilasi tetrahidrofuran disimpan dalam botol vakum yang berisi molecular sieve. Peralatan utama yang digunakan dalam penelitian ini meliputi peralatan sintesis yakni labu Schlenk $100 \mathrm{~mL}$, syringe 10 $\mathrm{mL}, 1 \mathrm{~mL}$, pompa vakum, rotary evaporator, pelat kromatografi lapis tipis, kolom kromatografi, serta perlatan analisis yang meliputi spektrometer massa Shimadzu resolusi tinggi dan spektrometer NMR Jeol dengan 
frekuensi $500 \mathrm{mHz}$ untuk ${ }^{1} \mathrm{H}$ dan 125 mHz untuk ${ }^{13} \mathrm{C}$.

\section{Prosedur Penelitian}

\section{Prosedur Arilasi n-oktilsilan dengan 2-iodida-5-metil tiofen}

Sebanyak $5 \mathrm{mmol}$ diazabisiklo(2,2,2)oktan dan $0,05 \mathrm{mmol}$ paladium tersier tributilfosfin dimasukkan dalam labu Schlenk $100 \mathrm{~mL}$ dan divakum selama 30 menit. Setelah proses vakum selesai dilakukan injeksi ke dalam labu Schlenk tersebut menggunakan syringe secara berturutturut sebanyak 4 mmol 2-iodida-5-metil tiofen, 1 mmol n-oktilsilane dan tetrahidrofuran sebanyak $3 \mathrm{~mL}$. Reaksi dilakukan dalam kondisi atmosfir argon selama 3 hari dengan pengaliran gas argon secara terus-menerus menggunakan balon yang telah terisi gas argon. Produk arilasi dimonitor menggunakan pelat kromatografi silika dengan pembanding senyawa 2-iodida-5metil tiofen. Produk arilasi yang terbentuk dipekatkan dengan rotary evaporator dan dipisahkan menggunakan kromatografi kolom silika dengan eluen yang digunakan yakni etil asetat. Produk arilasi murni yang diperoleh kemudian dikarakterisasi lebih lanjut secara spektroskopi.

\section{Karakterisasi Produk Hasil Arilasi}

\begin{tabular}{l}
\multicolumn{1}{c}{ Produk } \\
dikarakterisasi \\
spektroskopi massa, spektroskopi ${ }^{1} \mathrm{H}$, \\
${ }^{13} \mathrm{C}$ dan DEPT-135 NMR.
\end{tabular}

\section{HASIL DAN PEMBAHASAN}

Reaksi arilasi n-oktilsilan
dengan 2-iodida-5-metil tiofen
menggunakan katalis paladium dalam
kondisi atmosfir argon dirangkum dalam
reaksi pada Gambar 1.

Terlihat pada Gambar 1 bahwa terjadi arilasi antara n-oktilsilan dengan 2-iodida-5-metil tiofen membentuk produk arilasi yakni tris(5-metil-2tiofen)oktilsilan dengan pelepasan tiga molekul hidrogen iodida yang dengan mudah dihilangkan pada proses ekstraksi dan pemurnian. Reaksi pada Gambar 1 di atas tidak akan berjalan dengan ketidakhadiran katalis paladium. Katalis paladium diketahui sebagai katalis yang banyak digunakan dalam reaksi kopling disamping rhodium maupun iridium (Murata, et al., 2002). Hasil penelitian menunjukkan bahwa tanpa kehadiran katalis paladium reaksi tidak berjalan membentuk prosuk arilasi walaupun reaksi dilakukan selama sepuluh hari. Hal ini ditunjukkan dari tidak adanya noda baru pada pelat kromatografi lapis tipis yang dibandingkan dengan noda standar berupa senyawa n-oktilsilan maupun 2-iodida-5-metil tiofen. Reaksi diatas merupakan reaksi pengembangan dari reaksi arilasi yang telah dilakukan oleh Lesbani, dkk. (2012b) yang menggunakan berbagai aril iodida maupun organosilika. Akan tetapi organosilika yang digunakan pada umumnya bukan merupakan rantai alifatik. Walaupun Lesbani, dkk. (2013c) telah melaporkan keberhasilan arilasi antara aril halida dengan oktadesilsilan yang merupakan organosilika rantai panjang namun pengembangan arilasi dengan organosilika alifatik memiliki keunikan dan peluang bagi sintesis senyawa organik yang lebih kompleks. Pada penelitian ini digunakan noktilsilan dengan jumlah rantai karbon hingga delapan sehingga dengan terbentuknya produk arilasi berarti memberikan peluang bagi pengembangan reaksi arilasi menggunakan senyawa alifatik dengan variasi panjang rantai yang beragam. 
Penggunaan katalis paladium dalam reaksi arilasi... (Aldes Lesbani, dkk.)

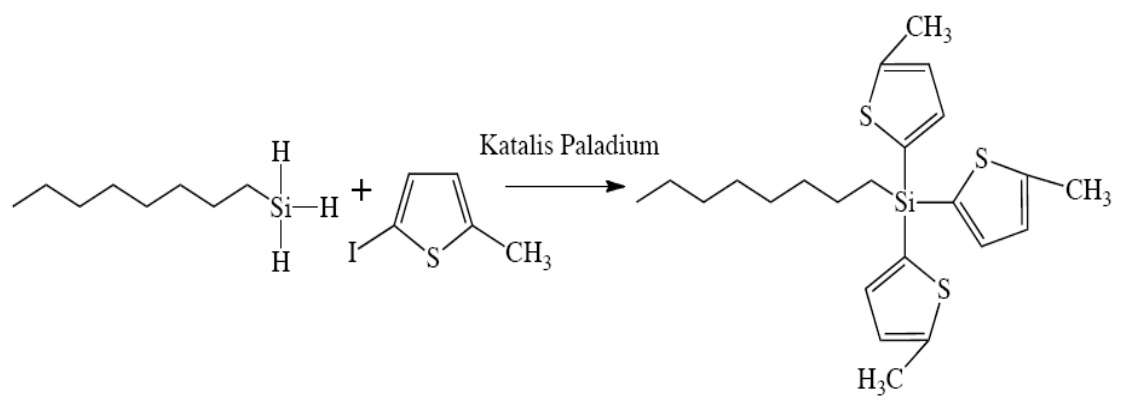

Gambar 1. Reaksi arilasi n-oktilsilan dengan 2-iodida-5-metil tiofen

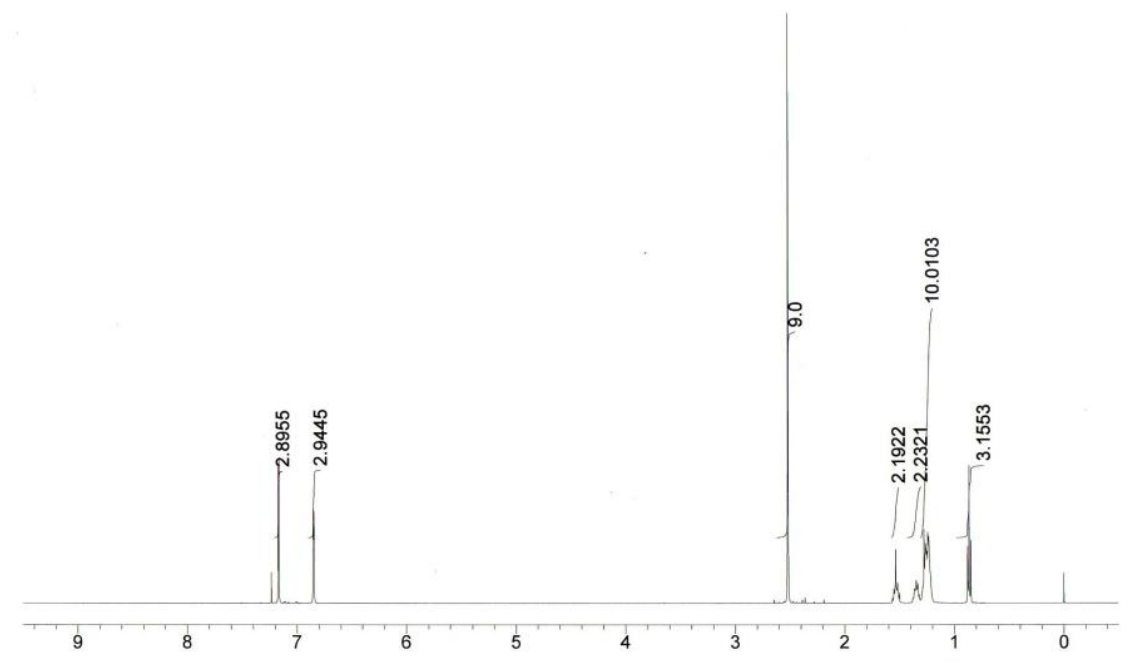

Gambar 2. Spektra ${ }^{1} \mathrm{H}$ NMR senyawa hasil arilasi

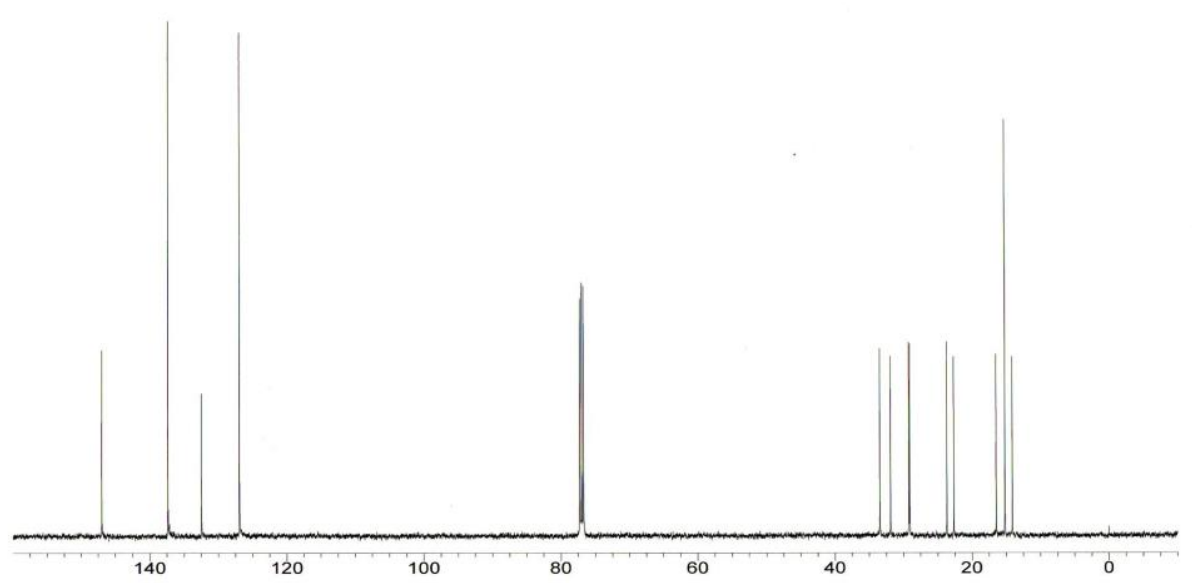

Gambar 3. Spektra ${ }^{13} \mathrm{C}$ NMR senyawa hasil arilasi 
Selanjutnya dilakukan proses ekstraksi menggunakan diklorometan sebagai pelarut dan permurnian menggunakan kolom kromatografi silika dengan eluen etil asetat. Produk arilasi dimonitor menggunakan kromatogtafi lapis tipis silika dengan pembanding senyawa 2iodida-5-metil tiofen. Produk arilasi yang merupakan senyawa target diperoleh berupa cairan tak berwarna dengan persentase sebesar $30 \%$. Walaupun persentase produk arilasi yang diperoleh tidak besar, akan tetapi dengan terbentuknya produk arilasi pada reaksi pada Gambar 1 maka memberikan peluang bagi pengembangan sintesis senyawa-senyawa dengan reaktan senyawa alifatik rantai panjang. Untuk memastikan produk arilasi yang terbentuk sesuai dengan reaksi pada Gambar 1 maka dilakukan karakterisasi dengan menggunakan spektrometer ${ }^{1} \mathrm{H}$ NMR dan ${ }^{13} \mathrm{C}$ NMR serta DEPT-135 untuk memastikan gugus alifatik yang terdapat pada produk arilasi (Solomon and Fryhle, 2008).

\section{Spektra ${ }^{1} \mathrm{H}$ dan ${ }^{13} \mathrm{C}$ NMR produk} arilasi tersaji pada Gambar 2 dan 3 . Gambar 2 menunjukkan adanya tujuh proton ekivalen yang terdapat pada produk arilasi yakni pada pergeseran kimia $\delta 0,86 \mathrm{ppm}(\mathrm{t}, 3 \mathrm{H}, J=7 \mathrm{~Hz}), 1,23$ $1,28 \mathrm{ppm}(\mathrm{m}, 10 \mathrm{H}), 1,34 \mathrm{ppm}(\mathrm{t}, 2 \mathrm{H}, J=$ 7,3 Hz), 1,52 ppm (q, 2H, $J=7,9 \mathrm{~Hz})$, 2,52 ppm (s, 9H), 6,85 ppm (q, 3H, $J=$ $1,0 \mathrm{~Hz})$, dan $7,17 \mathrm{ppm}(\mathrm{d}, 3 \mathrm{H}, J=3,4$ $\mathrm{Hz}$ ). Dengan jumlah total proton yang ada hasil integrasi maka terdapat sebanyak 32 buah proton ekivalen pada produk arilasi. Bila dihitung secara teoritik jumlah proton produk arilasi pada Gambar 1 maka terdapat sebanyak 32 buah proton. Hal ini menunjukkan bahwa produk arilasi berhasil disintesis. Terlihat pula pada spektrum ${ }^{1} \mathrm{H}$ NMR pada Gambar 2 tidak terdapat puncak proton lain yang mengindikasikan kemurnian senyawa hasil arilasi. Untuk memperkuat hasil karakterisasi ini maka dilakukan identifikasi menggunakan spektrometer ${ }^{13} \mathrm{C}$ NMR dengan spektra pada Gambar 3.

Pada Gambar 3 terlihat bahwa terdapat 13 buah puncak karbon ekivalen. Bila dihitung secara seksama jumlah karbon pada produk arilasi Gambar 1 terdapat 13 buah karbon ekivalen dengan rincian delapan buah karbon alifatik, satu karbon metil pada gugus tiofen, dua karbon pada gugus tiofen dan dua karbon tiofen kuartener pada gugus tiofen. Ketigabelas karbon ekivalen tersebut yakni tersebar pada pergeseran kimia $\delta 14,1 \mathrm{ppm}\left(\mathrm{CH}_{3}\right), 15,2$ ppm $\left(\mathrm{CH}_{3}\right), 16,4$ ppm $\left(\mathrm{CH}_{2}\right), 22,7 \mathrm{ppm}$ $\left(\mathrm{CH}_{2}\right), 23,7 \mathrm{ppm}\left(\mathrm{CH}_{2}\right), 29,1 \mathrm{ppm}\left(\mathrm{CH}_{2}\right)$, 29,2 ppm $\left(\mathrm{CH}_{2}\right), 31,9 \mathrm{ppm}\left(\mathrm{CH}_{2}\right), 33,4$ ppm $\left(\mathrm{CH}_{2}\right), 126,9 \mathrm{ppm}(\mathrm{CH}), 132,5 \mathrm{ppm}$ (Cq), 137,4 ppm (CH), dan 147,0 ppm (Cq). Hasil pengukuran ${ }^{13} \mathrm{C}$ NMR yang dikorekasikan dengan pengukuran DEPT-135 seperti yang tersaji pada Gambar 4 terlihat bahwa karbon $-\mathrm{CH}_{2}$ sebanyak tujuh puncak mengarah ke bawah dari pergeseran kimia $\delta 22,7-33,4$ ppm dan karbon kuartener $\mathrm{Cq}$ tak muncul pada pengukuran yakni pada pergeseran kimia $\delta 132,5$ ppm dan 147,0 ppm. Berdasarkan hasil pengukuran ${ }^{13} \mathrm{C}$ dan DEPT-135 NMR ini maka dipastikan bahwa senyawa yang terbentuk merupakan senyawa arilasi sesuai Gambar 1 dengan nama tris(5metil-2-tiofen)oktilsilan. Akan tetapi untuk melengkapi hasil analisis terhadap produk arilasi maka digunakan pengukuran menggunakan spektroskopi massa resolusi tinggi 


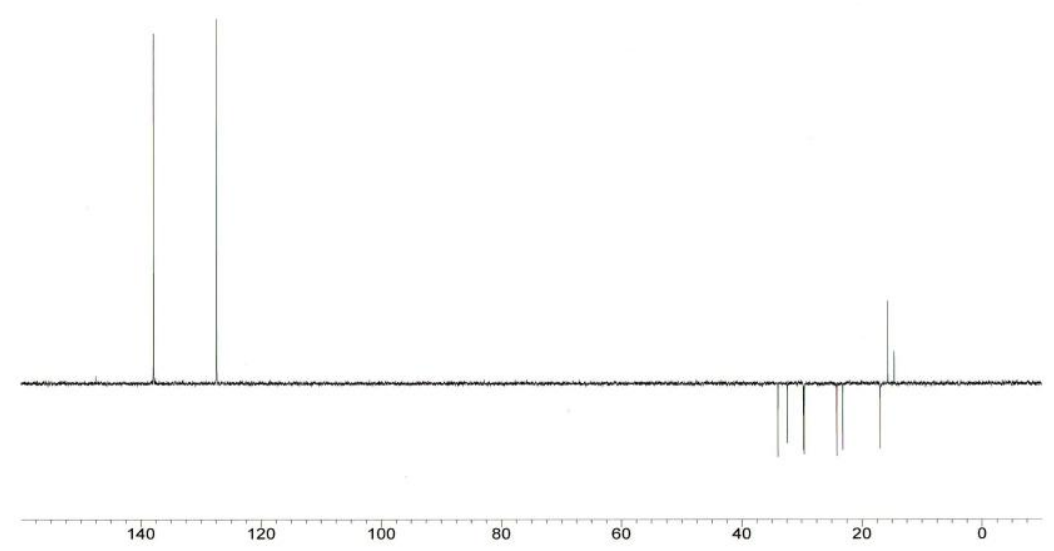

Gambar 4. Spektra DEPT-135 senyawa hasil arilasi

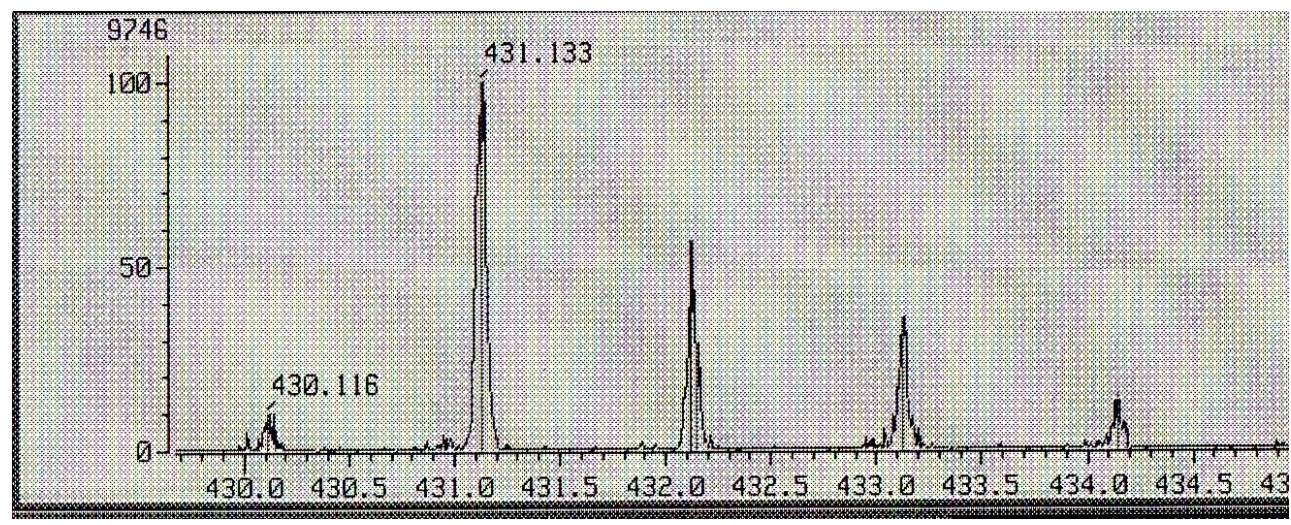

Gambar 5. Spektrum massa resolusi tinggi dan komposisi unsur senyawa hasil arilasi

Pengukuran dengan spektroskopi massa resolusi tinggi menghasilkan data spektra massa dengan komposisi unsur (elemental analysis) seperti disajikan pada Gambar 5.

Gambar 5 menunjukkan bahwa puncak ion molekul senyawa arilasi yakni pada $\mathrm{m} / \mathrm{z}$ 432. Secara teoritik, komposisi unsur senyawa hasil arilasi yakni $\mathrm{C}_{23} \mathrm{H}_{32} \mathrm{SiS}_{3}$. Proses pemilihan puncak ion molekul terbaik ditandai dengan persentase kesalahan analisis yang kecil dengan tingkat toleransi sebesar (+/-) $10 \mathrm{mmu}$. Hasil pemilihan puncak ion molekul terbaik seperti pada Gambar 5 yakni pada $\mathrm{m} / \mathrm{z}$ sebesar 432,1473 dengan tingkat kesalahan +3 mmu. Puncak ion molekul lain yang muncul menghasilkan tingkat kesalahan analisis yang lebih besar dari (+/-) 10 mmu. Dari data spektroskopi massa resolusi tinggi ini maka semakin memperkuat bahwa produk arilasi seperti pada reaksi Gambar 1 antara noktilsilan dengan 2-iodida-5-metil tiofen telah terbentuk dengan adanya katalis paladium.coli yang tumbuh.

\section{KESIMPULAN}

Arilasi n-oktilsilan dengan 2iodida-5-metil tiofen menggunakan katalis paladium menghasilkan senyawa tris(5-metil-2-tiofen)oktilsilan yang berupa cairan bening. Senyawa yang 
dihasilkan memiliki rendemen sebesar $30 \%$. Karakterisasi dengan spektroskopi massa menghasilkan nilai $\mathrm{m} / \mathrm{z}$ sebesar 432. Hasil pengukuran menggunakan spektroskopi ${ }^{1} \mathrm{H}$ NMR menghasilkan tujuh proton ekivalen yakni pada pergeseran kimia $\delta 0,86 \mathrm{ppm}(\mathrm{t}, 3 \mathrm{H}, J=$ $7 \mathrm{~Hz}), 1,23-1,28 \mathrm{ppm}(\mathrm{m}, 10 \mathrm{H}), 1,34$ ppm (t, 2H, $J=7,3 \mathrm{~Hz}), 1,52 \mathrm{ppm}(\mathrm{q}$, $2 \mathrm{H}, J=7,9 \mathrm{~Hz}), 2,52 \mathrm{ppm}(\mathrm{s}, 9 \mathrm{H}), 6,85$ ppm (q, 3H, $J=1,0 \mathrm{~Hz}$ ), dan 7,17 ppm (d, $3 \mathrm{H}, \quad J=3,4 \mathrm{~Hz}$ ). Pengukuran menggunakan spektroskopi ${ }^{13} \mathrm{C}$ NMR menghasilkan tiga belas karbon ekivalen yang kemudian dikonfirmasi dengan DEPT-135 yakni pada pergeseran kimia $\delta 14,1 \mathrm{ppm}\left(\mathrm{CH}_{3}\right), 15,2 \mathrm{ppm}\left(\mathrm{CH}_{3}\right), 16,4$ ppm $\left(\mathrm{CH}_{2}\right), 22,7$ ppm $\left(\mathrm{CH}_{2}\right), 23,7 \mathrm{ppm}$ $\left(\mathrm{CH}_{2}\right), 29,1 \mathrm{ppm}\left(\mathrm{CH}_{2}\right), 29,2 \mathrm{ppm}\left(\mathrm{CH}_{2}\right)$, 31,9 ppm $\left(\mathrm{CH}_{2}\right), 33,4 \mathrm{ppm}\left(\mathrm{CH}_{2}\right), 126,9$ ppm (CH), 132,5 ppm (Cq), 137,4 ppm $(\mathrm{CH})$, dan 147,0 ppm (Cq).

\section{DAFTAR PUSTAKA}

Daiss, J.O., C. Burschka, J. S. Mills, J. G. Montana, G. A. Showell, I. Fleming, C. Gaudon, D. Ivanona, H. Gronemeyer, R. Tacke, 2005, Synthesis, Crystal Structure Analysis, and Pharmacological Characterization of Disilabexarotene, a Disila-Analogue of the RXR-Selective Retinoid Agonist Bexarotene, Organometallics, 24, 3192-3199.

Lesbani, A., H. Kondo, Y. Yabusaki, M. Nakai, Y. Yamanoi, H. Nishihara, 2010a, Integrated PalladiumCatalyzed Arylation of Heavier Group 14 Hydrides, Chemistry A European Journal, 16, 1351913527.

Lesbani, A., H. Kondo, J. I. Sato, Y. Yamanoi. H. Nishihara., 2010b, Facile Synthesis of Hypersilylated Aromatic Compounds by Palladium-
Mediated Arylation Reaction, Chemical Communications, 46, 7784-7786.

Lesbani, A., H. Kondo, Y. Yamanoi, N. Nishihara, 2012a, Sintesis Pestisida Flusilazol, Jurnal Kimia FMIPA Universitas Udayana, 6, 1-7.

Lesbani, A, R. Mohadi, 2012b, Tripel Arilasi Organosilika Primer Dengan Beberapa Aril Iodida Menggunakan Katalis Paladium, Chemistry Progress, 5,2, 66-69.

Lesbani, A., R. Mohadi, 2013a, Sintesis Tris(Tiofen)n-Butil Germanium Melalui Reaksi Arilasi Senyawa Tiofen Dengan n-Butil Germanium, Sains \& Matematika, 2,1, 1-5.

Lesbani, A., R. Mohadi, Eliza, Elfita. 2013b, Sintesis Tris(4thioanisil)Oktilsilan Melalui Reaksi Kopling, Chemistry Progress, 6,2, 45-49.

Lesbani, A., R. Mohadi, N. Hidayati, Elfita 2013c, Studi Reaksi Kopling Oktadesilsilan Dengan Aril Iodida Tersubstitusi Para, Jurnal Molekul, $8,1,58-65$.

Murata, M, M. Ishikura, M. Nagata, S. Watanabe, Y. Masuda, 2002, Rhodium(I)- Catalyzed Silylation of Aryl Halides With Triethoxysilane: PracticalSynthetic Route to Aryltriethoxysilanes, Organic Letters, 4,11, 1843-1845.

Negishi, E, 2002, Organopalladium Chemistry, New York: WileyInterscience.

Sato, K., M. Aoki, R. Noyori, 1998, A "Geeen" Route to Adipic Acid: Direct Oxidation of Cyclohexanes with 30 Percent Hydrogen Peroxide, Science, 281, 16461647. 
Penggunaan katalis paladium dalam reaksi arilasi... (Aldes Lesbani, dkk.)

Solomons, T.W.G, C.B. Fryhle, 2008, Organic Chemistry $9_{\text {th }}$ Edition, John Wiley \& Sons, Inc, USA.

Yamanoi, Y. 2005, Palladium-Catalyzed Silylations of Hydrosilanes With Aryl Halides Using Bulky Alkyl Phosphine, Journal of Organic Chemistry, 70, 8607-9609.

Yamanoi, Y., N. Nishihara, 2006, Rhodium-Catalyzed Silylation of
ortho-Functionalized Aryl Halides With Hydrosilanes, Tetrahedron Letters, 47, 7157-7161.

Trost, B. M, T. R. Verhoeven, 1982, Comprehensive Organometallic Chemistry, Pergamon, Oxford, UK.

Tsuji, J., 2004, Palladium Reagents and Catalyst, Chichester: Wiley. 